\title{
Development of a
} characterization methodology for postirradiation examination of miniature fuel specimens

Nuclear Technology

Research and Development

\author{
Prepared for \\ U.S. Department of Energy \\ Advanced Fuels Campaign \\ A.M. Raftery, R.N. Morris, K.R. Smith, \\ G.W. Helmreich, C.M. Petrie, \\ K.A. Terrani, A.T. Nelson \\ Oak Ridge National Laboratory \\ August 23, 2018 \\ M2NT-18OR020201051
}




\section{DISCLAIMER}

This information was prepared as an account of work sponsored by an agency of the U.S. Government. Neither the U.S. Government nor any agency thereof, nor any of their employees, makes any warranty,

expressed or implied, or assumes any legal liability or responsibility for the accuracy, completeness, or usefulness, of any information, apparatus, product, or process disclosed, or represents that its use would not infringe privately owned rights. References herein to any specific commercial product, process, or service by trade name, trade mark, manufacturer, or otherwise, does not necessarily constitute or imply its endorsement, recommendation, or favoring by the U.S. Government or any agency thereof. The views and opinions of authors expressed herein do not necessarily state or reflect those of the U.S. Government or any agency thereof. 


\section{SUMMARY}

The miniature fuel (MiniFuel) irradiation experimental design at Oak Ridge National Laboratory (ORNL) enables benchmark testing and separate effects testing of novel fuel types in the High Flux Isotope Reactor (HFIR) in support of the Advanced Fuels Campaign (AFC). The first round of MiniFuel subcapsules will be available for post-irradiation examination at the end of 2018. This report establishes the procedure for disassembly, fuel retrieval, post-irradiation analysis of the fission product behavior (fission gas release and fuel swelling), and microstructural characterization of the irradiated MiniFuel specimens. All methods were tested and validated out-of-cell and are ready to be implemented in-cell for use on the first set of irradiated MiniFuel specimens. The path forward regarding further characterization techniques is presented, which will involve analyzing other specimen geometries using the methods presented in this report and expanding the post-irradiation analysis of MiniFuel specimens to include additional properties. 
Development of a characterization methodology for

August 2018

This page is intentionally left blank. 


\section{CONTENTS}

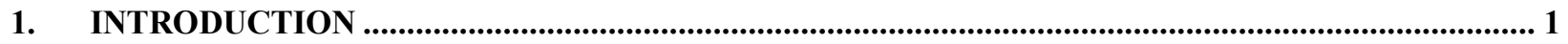

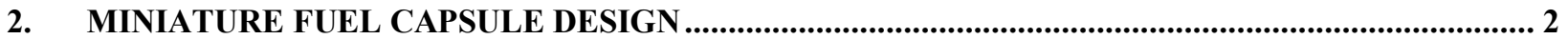

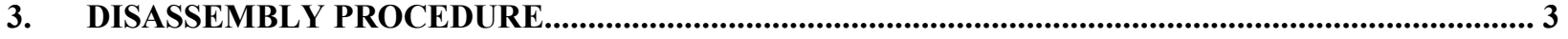

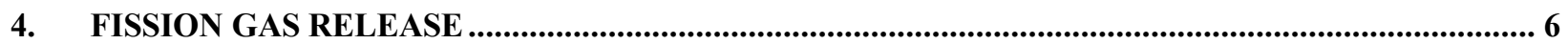

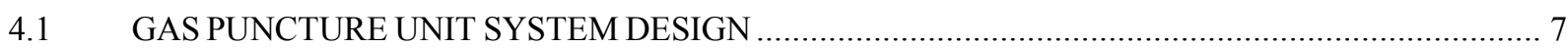

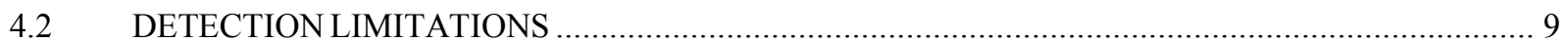

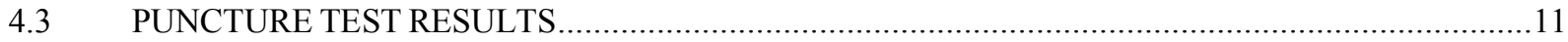

5. FUEL SWELLING ..........................................................................................................................12

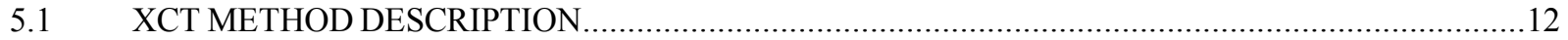

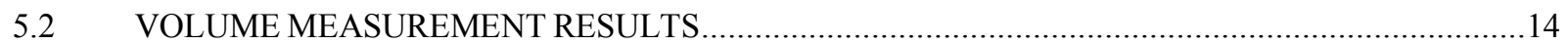

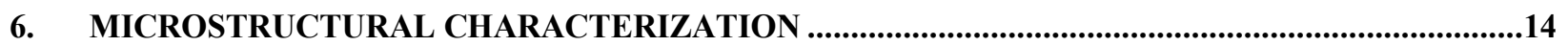

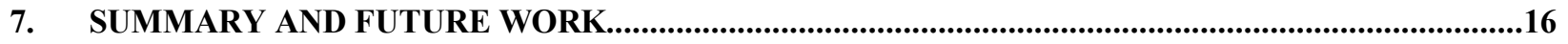

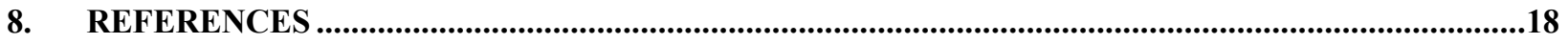

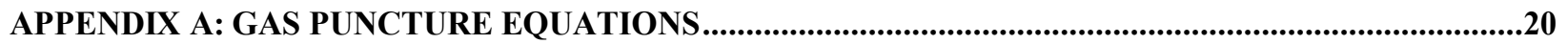


Development of a characterization methodology for post-irradiation examination of miniature fuel specimens

August 2018

This page is intentionally left blank. 


\section{FIGURES}

Figure 1. Schematic of the MiniFuel sub-capsule, target, and basket design [6] ................................

Figure 2. Molybdenum disk layout with (a) six $800 \mu \mathrm{m}$ UN kernels, (b) twenty-six $425 \mu \mathrm{m}$ UC Kernels, (c) one $3 \mathrm{~mm}$ disk, and (d) four $1 \mathrm{~mm}$ TRISO particles.........................................

Figure 3. Overview of MiniFuel disassembly procedure ...................................................................

Figure 4. (a) Images of M01 and MF02 targets before irradiation and (b) the corresponding radiography images with red lines where the cuts from the low speed saw will occur at the springs during disassembly.

Figure 5. Cutting fixture designed for cutting the MiniFuel sub-capsule, shown with sub-capsule loaded (a) before and (b) after testing the cutting with the low-speed saw.

Figure 6. (a) Capped sub-capsule shown in the cutting fixture after the cutting is complete and (b) removed from the fixture for transfer.

Figure 7. (a) IMGA cell where fuel retrieval will occur and (b) the scope/vacuum needle system that will be used to retrieve and sort the MiniFuel fuel specimens.

Figure 8. Schematic of gas puncture system design previously used for puncturing commercial spent fuel rods and now adapted for use with the MiniFuel sub-capsules [8]

Figure 9. Schematic of gas puncture system with components labeled............................................ 8

Figure 10. (a) Front and (b) top-down view of MiniFuel gas puncture unit shown out-of-cell during testing.

Figure 11. Puncture tool pictured after successful puncture with minimal dulling of the tip.

Figure 12. (a) Charcoal cold traps used to collect krypton gas and (b) the germanium detector used for counting the radioactivity from the gas.

Figure 13. Calculated $\mathrm{Kr}-85$ activity based on percentage of fission gas release................................... 10

Figure 14. Pressure evolution during puncture of MiniFuel test sub-capsule....................................... 11

Figure 15. Cross-section of pre-irradiation UN TRISO tomograph with coloration of segmented layers (left) and cross-section of tungsten carbide standard tomograph (right).

Figure 16. Two sizes of aluminum mounting forms $(3.18 \mathrm{~mm}$ diameter stub and $6.35 \mathrm{~mm}$ diameter stub) that can be used to mount irradiated fuel kernels in epoxy.

Figure 17. (a) Minimet polisher located in-cell and (b) the mounting form positioned inside of the thinning attachment for polishing [15]

\section{TABLES}

Table 1. Results for XCT software measurement of ball bearing standards of varying material and size. 


\section{ACRONYMS}

DOE-NE Department of Energy Office of Nuclear Energy

AFC

Advanced Fuels Campaign

LWR

Light-water Reactor

ATR

Advanced Test Reactor

INL

Idaho National Laboratory

ATF

Accident Tolerant Fuel

MiniFuel

Miniature Fuel

HFIR

High Flux Isotope Reactor

SET

Separate Effects Testing

TRISO

Tri-structural Isotropic

PIE

Post-irradiation Examination

VXF

Vertical Experimental Facility

IFEL

Irradiated Fuels Examination Laboratory

IMGA

Irradiated Microsphere Gamma Analyzer

$\mathrm{XCT}$

X-ray Computed Tomography

SEM

Scanning Electron Microscope

LAMDA

Low Activation Materials Development and Analysis

PCMI

Pellet-Clad Mechanical Interaction

AGR

Advanced Gas Reactor

EDS

Electron Dispersive X-ray Spectroscopy

WDS

Wave Dispersive X-ray Spectroscopy

FIB

Focused Ion Beam

TEM

Transmission Electron Microscopy 
This page is intentionally left blank. 


\section{ACKNOWLEDGMENTS}

This work was supported by the Advanced Fuels Campaign of the US Department of Energy Office of Nuclear Energy. The authors would like to express appreciation to a number of people who assisted in the completion of this work. Sarah Finkeldei is recognized for her preliminary testing of pycnometry methods and advice on the selection of the microbalance model to implement into the hot cell. David Bryant and Annabelle Le Coq helped with coordinating the location of extra MiniFuel parts for testing. Alan Frederick and Doug Kyle are acknowledged for welding of the test capsules. 
This page is intentionally left blank. 


\section{DEVELOPMENT OF METHODS FOR POST- IRRADIATION EXAMINATION OF MINIATURE FUEL SPECIMENS}

\section{INTRODUCTION}

In response to the 2011 events at the Fukushima Daiichi nuclear power plant, Congress began providing funding through the Department of Energy Office of Nuclear Energy (DOE-NE) to address the need for a fuel system with enhanced accident tolerance. The DOE-NE Advanced Fuels Campaign (AFC) was integrated with industry and university initiatives to perform research and development into advanced Light Water Reactor (LWR) fuel systems that could enhance the safety of current and future operating reactors [1]. Additional objectives of the campaign include the development of materials for advanced reactor technologies and the integration of experimental data into fuel performance codes. One highly recognized essential aspect of the development of advanced fuel systems is the irradiation testing of fuel materials. The fuel must withstand the effects of irradiation without extreme degradation of fuel material properties. Therefore, the results of irradiation testing are used to validate whether a fuel can be safely and efficiently used to operate a nuclear reactor.

Currently, the main resource for irradiation testing of fuels in the US is the Advanced Test Reactor (ATR) at Idaho National Laboratory (INL). Large integral fuel campaigns are typically conducted to test fuelcladding concepts in-reactor, which requires appreciable resources. In addition, testing space in the reactor is limited and typically in high demand. Improvements in fuel design and fabrication techniques are rapidly occurring, and the pursuit of Accident Tolerant Fuels (ATFs) and other advanced fuel concepts means that an increasing number of novel fuel types are going to reach the stage of irradiation testing. Consequently, there is a direct need for an additional resource for benchmark or proof-ofprincipal testing of novel fuels.

The Miniature Fuel (MiniFuel) irradiation testing approach at Oak Ridge National Laboratory has been established to meet the need for efficient testing of novel fuel types and separate effects testing of fuel materials [2]. This concept uses a technique of irradiating very small fuel specimens in the High Flux Isotope Reactor (HFIR) to gain insight on the irradiation behavior of fuel materials. The small fuel specimen size provides the ability to perform screening tests on fuel concepts before full-scale irradiation campaign experiments, which could highlight poor or unexpected behavior much earlier than the traditional approach. Preliminary data on the fuel type will be collected to determine whether the concept is appropriate for further full-scale testing.

The MiniFuel testing strategy will also be able to provide separate effects data for the more traditional fuel concepts. The Separate Effects Testing (SET) methodology can provide data on thermal, mechanical, and fission product behavior with respect to individually varying external parameters (temperature, burnup). The MiniFuel design allows for these separate effects to be isolated and understood. For example, the small size of the fuel specimen eliminates the typical temperature gradient seen in full size fuel irradiations, meaning the irradiation behavior at fixed temperatures can be investigated [3]. These type of separate effects studies will provide valuable data that can be implemented into fuel performance codes (BISON, etc). Furthermore, HFIR allows accelerated studies due to the reactor's high flux and corresponding ability to reach high burnup in a short amount of time. The current plan is for the MiniFuel design to be used initially for separate effects testing of $\mathrm{UO}_{2}, \mathrm{UN}$, and $\mathrm{U}_{3} \mathrm{Si}_{2}$ [4]. 
The first three MiniFuel targets were loaded into HFIR for irradiation in June of 2018 [5]. The subcapsules contained either six kernels of uranium nitride (UN) fuel or four particles of tri-structural isotropic (TRISO) fuel. This document summarizes the procedure that will be used for retrieval and postirradiation examination (PIE) of these specimens and future specimens irradiated using the MiniFuel design. The process for target disassembly, fuel retrieval, and characterization of the fission product behavior is outlined. The path forward for testing of various geometries and expanding the postirradiation characterization to include additional material properties is also presented.

\section{MINIATURE FUEL CAPSULE DESIGN}

Figure 1 shows the configuration of the MiniFuel sub-capsule, target, and basket design. The full internals for a sub-capsule containing kernels are also detailed in this drawing. Each sub-capsule contains a molybdenum tube, molybdenum cup, $\mathrm{SiC}$ thermometry, the fuel specimens, and approximately five pieces of graphite foil that act as insulators and ensure a tight fit of all contents [5]. The sub-capsule housing is made of titanium and the internals were designed for efficient heat conduction during irradiation. The irradiation temperature is controlled by the gap between the sub-capsule and target housing [3].

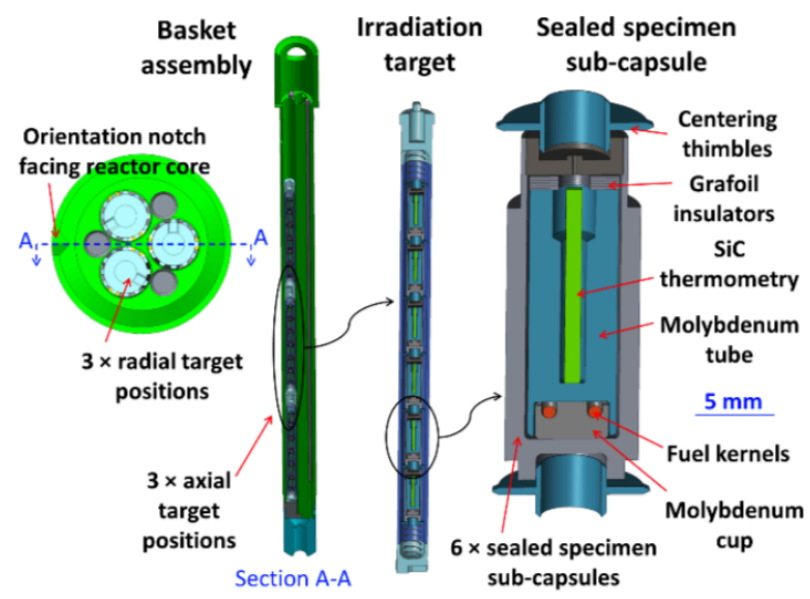

Figure 1. Schematic of the MiniFuel sub-capsule, target, and basket design [6].

The molybdenum cup within the sub-capsule holds the fuel specimens and is easily adapted to hold various fuel geometries, including a range of kernel sizes as well as thin disks. Figure 2 shows the various configurations that currently exist to test fuel specimens. Adaptations to include other small-sized geometries can easily be made, which provides numerous possibilities for a test matrix design.

(a)

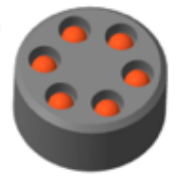

(c)

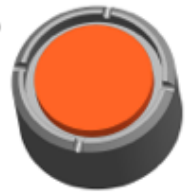

(b)

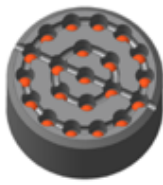

(d)

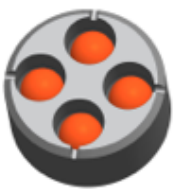

Figure 2. Molybdenum disk layout with (a) six $800 \mu \mathrm{m}$ UN kernels, (b) twenty-six $425 \mu \mathrm{m}$ UC Kernels, (c) one $3 \mathrm{~mm}$ disk, and (d) four $1 \mathrm{~mm}$ TRISO particles. 
Six sub-capsules are loaded into each target with centering thimbles on each side of the individual subcapsules and compression springs on each end of the target to hold them in place. Each target is loaded into a basket, which can accommodate up to nine targets for irradiation at any time. The baskets are irradiated in a vertical experimental facility (VXF) location in HFIR, which are located in the reflector of the reactor. The targets within the basket are cooled by direct contact with the primary coolant during irradiation.

\section{DISASSEMBLY PROCEDURE}

After shipment of the basket from HFIR, disassembly will take place at the Irradiated Fuels Examination Laboratory (IFEL) hot cell facility. The procedure for disassembly of the MiniFuel sub-capsules has been designed to ensure that the integrity of the small specimens is maintained until final retrieval. Figure 3 includes an overview of the disassembly procedure and the location where each step will take place.

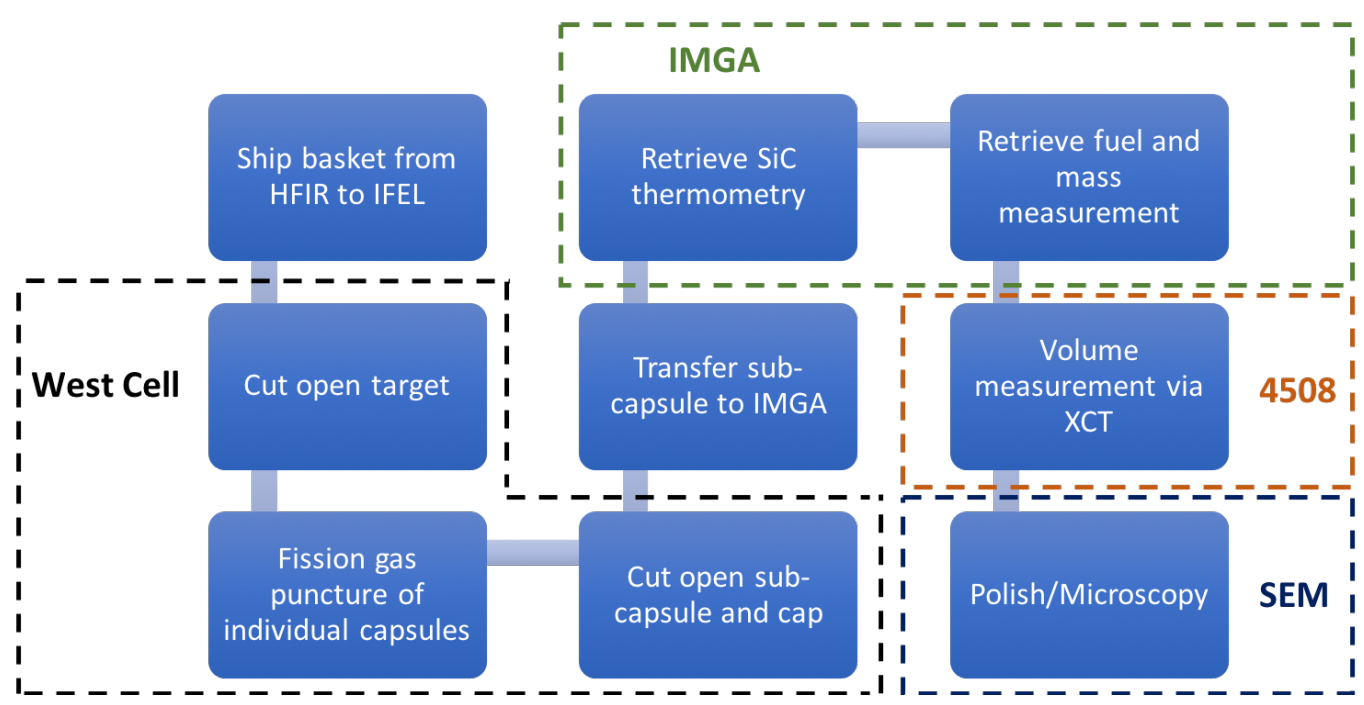

Figure 3. Overview of MiniFuel disassembly procedure.

First, the targets are cut open using a low speed diamond saw, which is located in the west cell at IFEL. The cut on each end of the target will take place where the springs are located, which is shown for loaded targets in Figure 4 ( $a$ and b). After cutting open the ends, the six individually sealed sub-capsules are gently removed from the target by pushing a rod through one end of the open target. Pushing the subcapsules out of the target is necessary due to the tight fit of the spacers that are located between the subcapsules.

Once the capsules have been removed from the target, each capsule will be punctured to measure the fission gas released from the fuel during irradiation. The fission gas puncture system design and puncture procedure are described thoroughly in Section 4. 
(a)

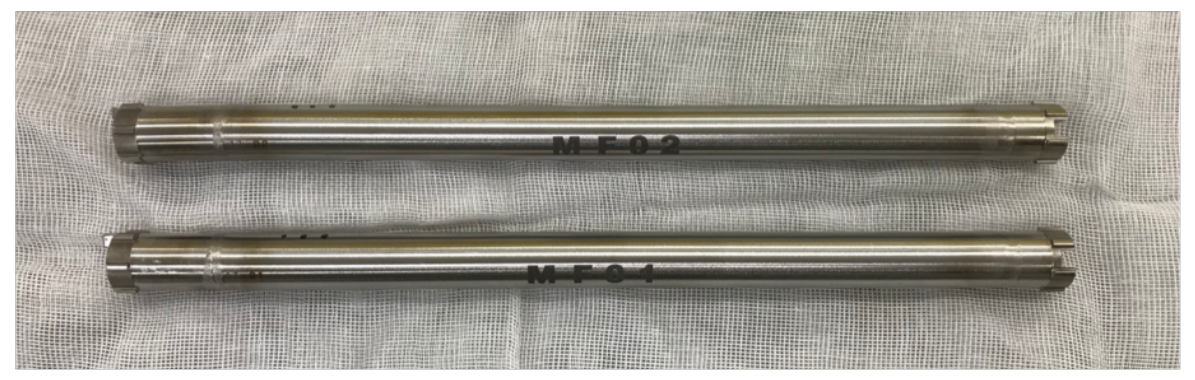

(b)

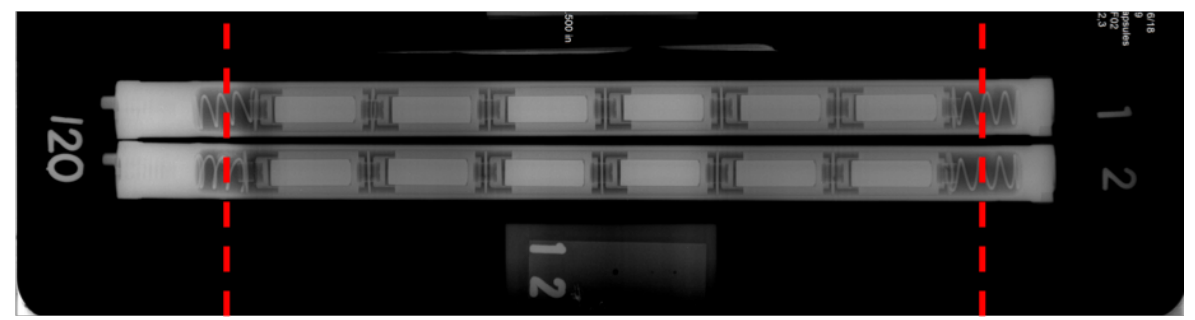

Figure 4. (a) Images of M01 and MF02 targets before irradiation and (b) the corresponding radiography images with red lines where the cuts from the low speed saw will occur at the springs during disassembly.

After puncture, the individual capsules will be cut open on a low-speed saw that has been configured to operate so that the blade comes in perpendicular in order to cut an upright sub-capsule. This orientation of the saw is used so there will be little risk of the specimens falling out inside of the main cell and scattering during cutting, since visual limitations may prevent locating the specimens once loose in this cell. A cutting fixture has been specifically designed for this purpose and is pictured in Figure 5 ( $a$ and $b$ ). The capsule is placed into the fixture, and the vice is tightened to secure the capsule in place for cutting.

(a)

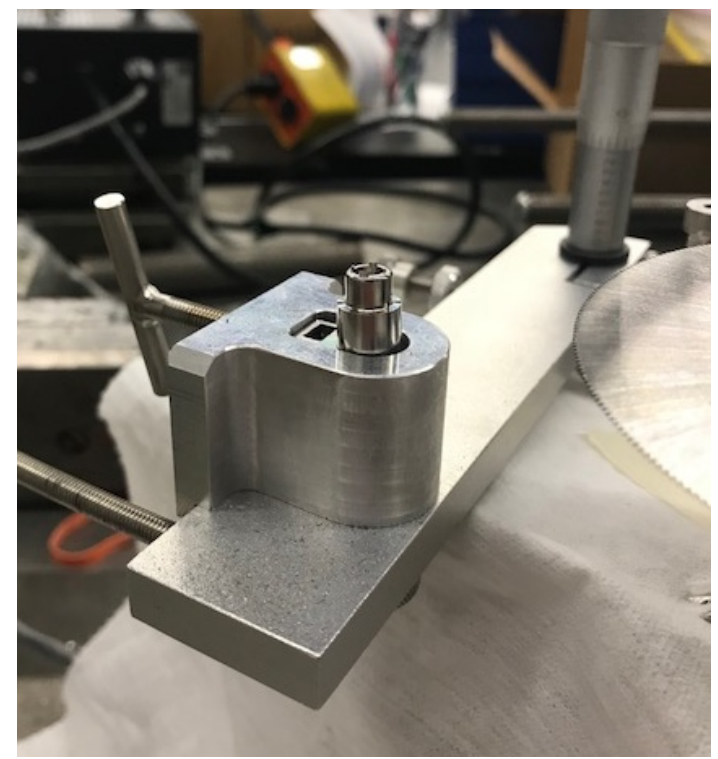

(b)

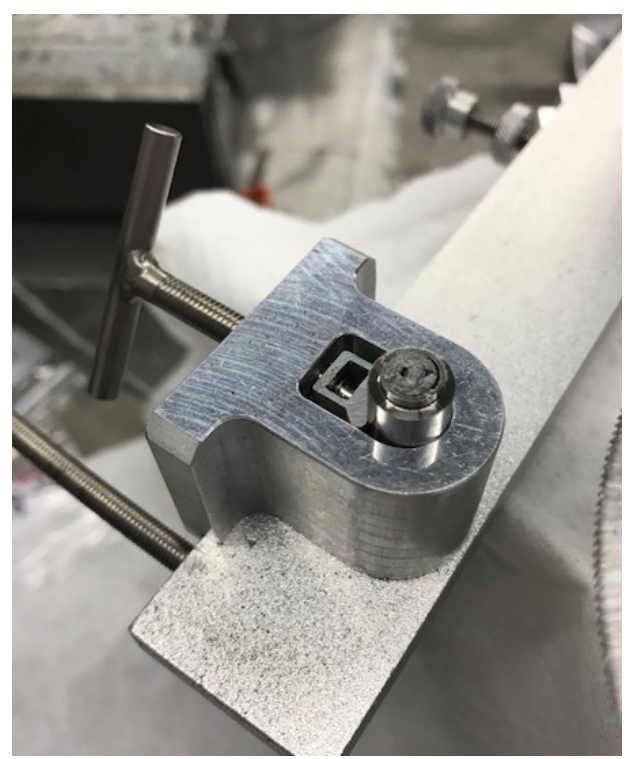

Figure 5. Cutting fixture designed for cutting the MiniFuel sub-capsule, shown with sub-capsule loaded (a) before and (b) after testing the cutting with the low-speed saw.

The cut on the sub-capsule is made $0.4 \mathrm{~mm}$ above the location where the puncture has occurred in order to avoid cutting the thermometry and inner molybdenum piece within the sub-capsule. After the subcapsule is cut open, it will be capped for transfer to another cell for thermometry and fuel retrieval. The small specimen size, limited specimen quantity, and visual limitations in the main cells at IFEL require 
that the handling and retrieval of the fuel specimens occur in another cell. Therefore, the capped specimen will be transferred to the Irradiated Microsphere Gamma Analyzer (IMGA) cell at IFEL, which is equipped with a vacuum needle handling tool and a stereo microscope that will be used for fuel specimen retrieval and placement into handling containers. The sub-capsule can be capped while still in the cutting fixture and removed afterwards for transfer by loosening the fixture vice. Figure 6(a) shows an out-of-cell image of the capped sub-capsule still in the fixture and Figure 6(b) shows the sub-capsule removed and ready for transfer. The plastic cap is a $3 \mathrm{D}$ printed piece that can be easily altered to create a tight fit on the outer diameter of the sub-capsule, since that parameter may vary depending on the specific MiniFuel experiment.

(a)

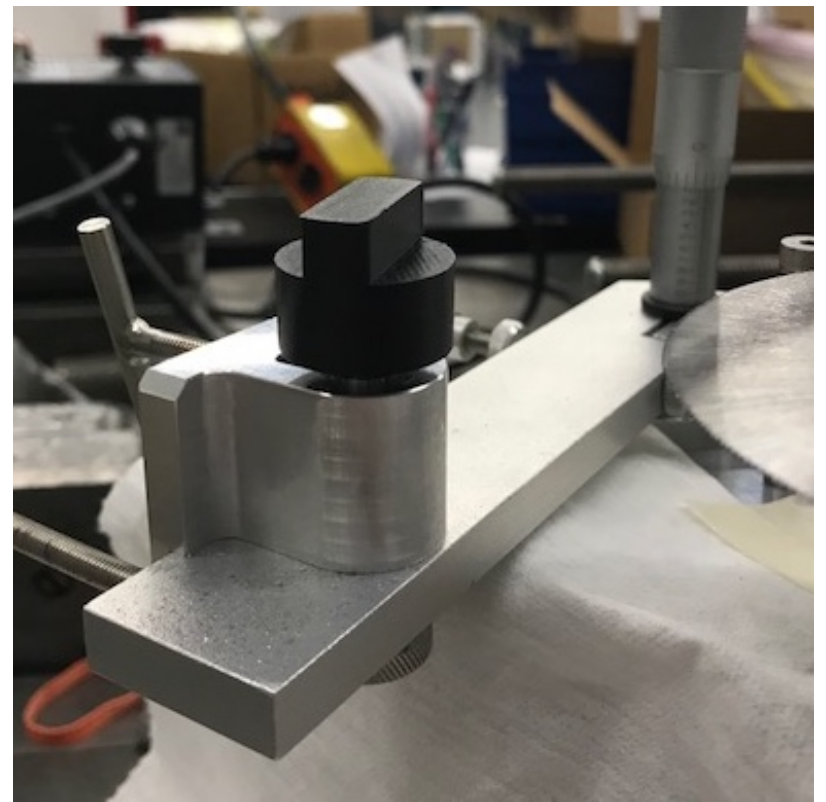

(b)

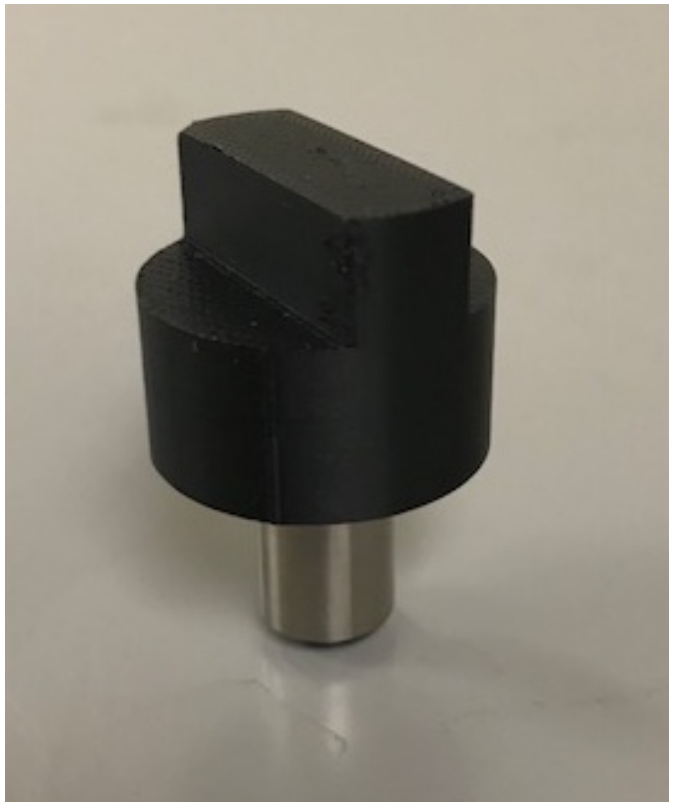

Figure 6. (a) Capped sub-capsule shown in the cutting fixture after the cutting is complete and (b) removed from the fixture for transfer.

The fuel specimens will be removed from the sub-capsule within the IMGA cell, which is pictured in Figure 7(a). The remotely operated scope and vacuum needle and stereo microscope, shown in Figure 7(b), will be used for viewing, photographing, and retrieval of the fuel specimens. The molybdenum piece must be removed before the fuel specimens can be retrieved; threads are located inside of the molybdenum piece for ease of removal. The fuel specimens will be emptied from the sub-capsule, sorted using the vacuum needle, and individually massed on a Mettler Toledo WXTP26 microbalance, which has a $1 \mu \mathrm{g}$ readability.

The post-irradiation volume of the fuel specimens will be measured to determine the extent of fuel swelling resulting from irradiation. The volume of each kernel will be measured using x-ray computed tomography (XCT) and a post-processing program specifically designed to analyze the XCT data for volume determination. The fuel specimens will be transferred in a lead pig from IFEL to Building 4508, which contains the XCT machine. A description of the process and the method used for validation of the XCT program is covered extensively in Section 5. The mass measurement will be used with the volume measurement to determine the post-irradiation density of the fuel specimen. 
(a)

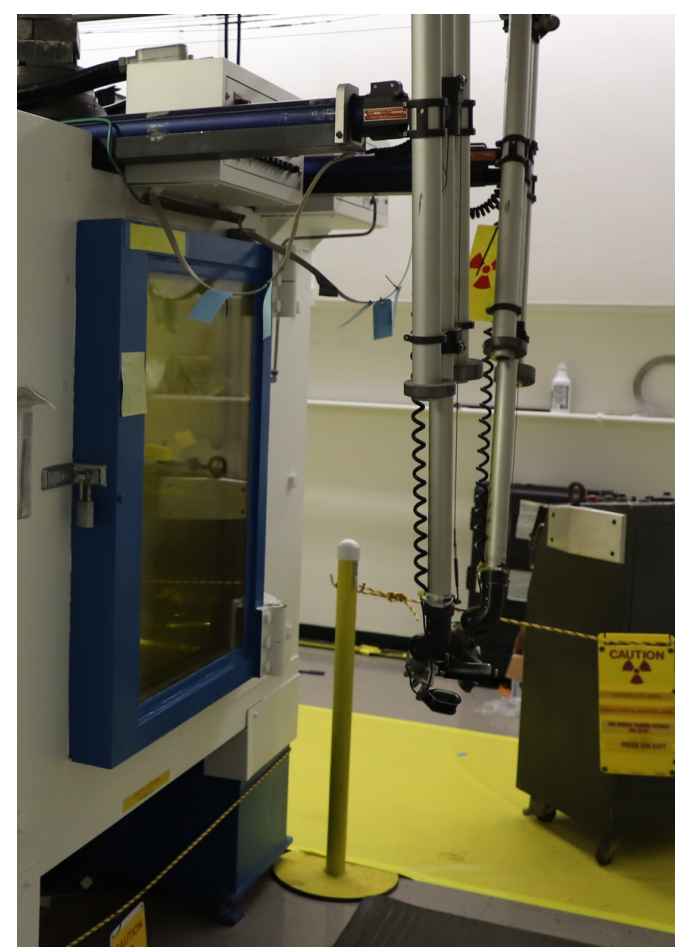

(b)

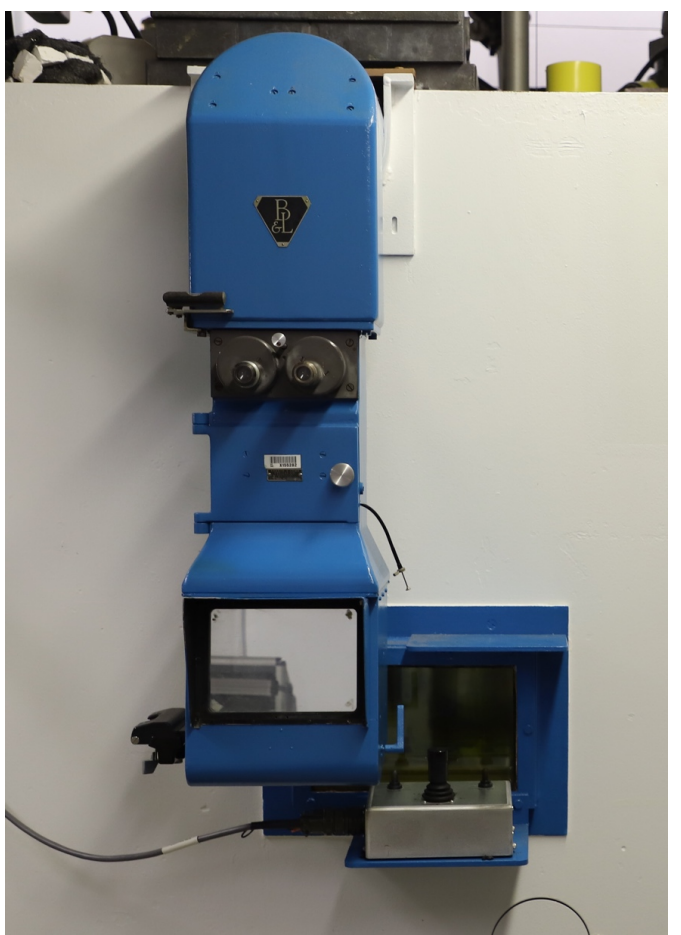

Figure 7. (a) IMGA cell where fuel retrieval will occur and (b) the scope/vacuum needle system that will be used to retrieve and sort the MiniFuel fuel specimens.

Microstructural characterization will be the final step in the MiniFuel post-irradiation examination procedure. The samples will be prepared in-cell and analyzed with the Scanning Electron Microscope (SEM) located at IFEL. Further characterization can occur at the Low Activation Materials Development and Analysis (LAMDA) Laboratory, which contains a variety of microscopes used for characterization of irradiated materials. The process for the metallographic preparation of the specimens at IFEL is described in Section 6.

\section{FISSION GAS RELEASE}

The process of fission during irradiation creates a range of solid and gaseous fission products within the fuel. The gaseous fission products cannot easily dissolve into the fuel material matrix and will therefore diffuse through the fuel until they escape into the plenum [7]. Excessive fission gas release from the fuel pellet to the fuel-clad gap and plenum poses a number of challenges, foremost by increasing the inventory of radionuclides that would be easily released to primary containment in the event of a cladding failure. For this reason, the ability of LWR fuel to retain fission gas products is considered a beneficial property. The post-irradiation fission gas release measurement via puncture of the MiniFuel sub-capsule is therefore used as one parameter to evaluate the ability of a fuel type to retain fission gas products. The titanium housing of the MiniFuel sub-capsule is punctured to release the gaseous fission products, which are then collected via a helium sweep gas system cryogenically in a charcoal cold trap. The measured release is indicative of the mobility of fission products within the fuel during irradiation. 


\subsection{GAS PUNCTURE UNIT SYSTEM DESIGN}

The MiniFuel fission gas puncture system design is based on a previous ORNL design for a gas puncture system that was used to evaluate the fission gas release of commercially irradiated fuel rods [8]. The system consists of a series of components that are arranged to puncture the sub-capsule housing and carry the released fission gas to cold traps for collection and subsequent detection. Figure 8 shows a schematic of all of the components in the system, most of which are located outside of the hot cell; the gas puncture unit is the only component located in-cell during the test. The complete procedure for puncturing includes measuring the internal free volume of the system in order to back-calculate the pressure inside of the gas plenum [8]. Figure 9 shows a picture of all components of the gas puncture system that are located out-ofcell.

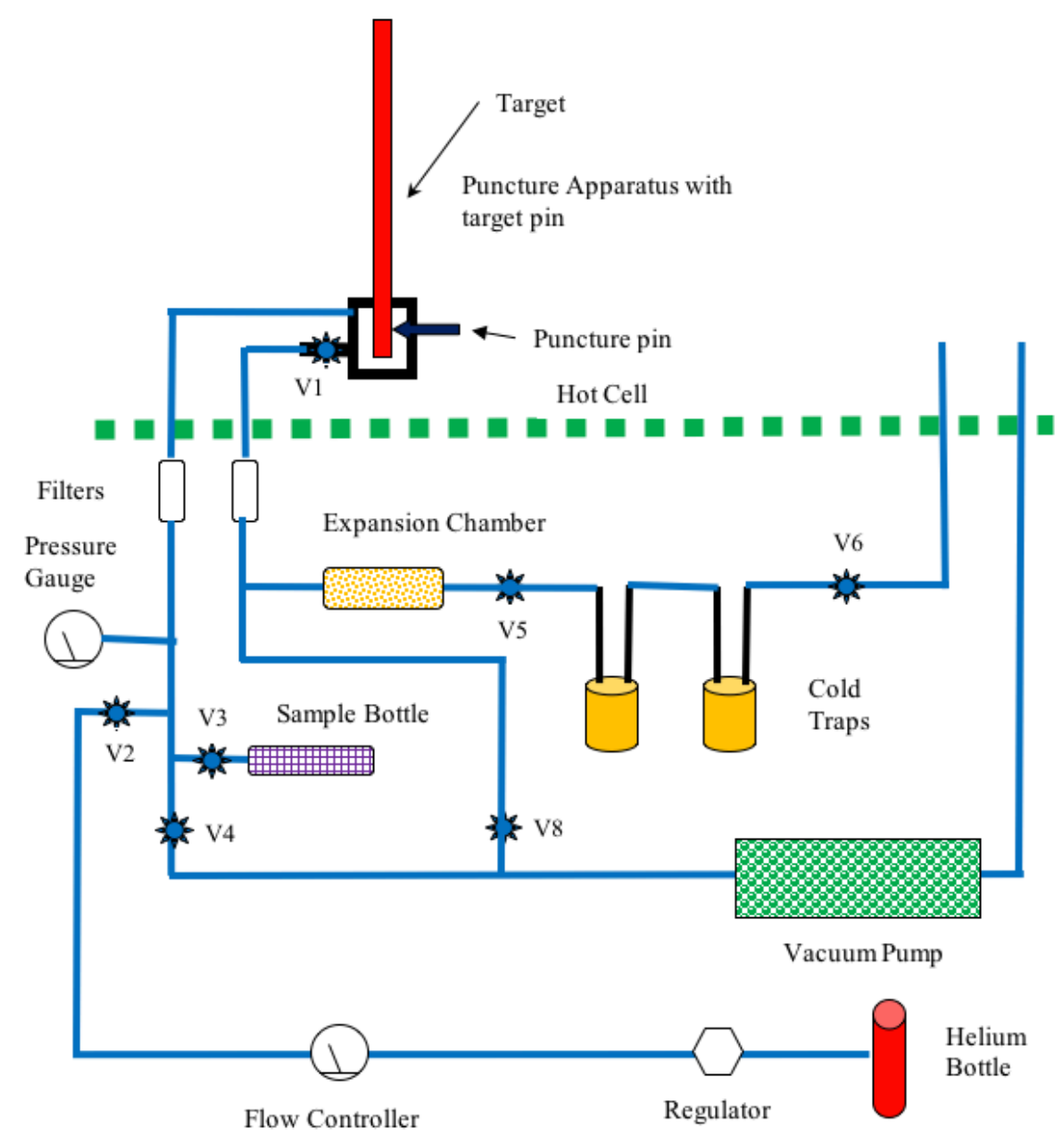

Figure 8. Schematic of gas puncture system design previously used for puncturing commercial spent fuel rods and now adapted for use with the MiniFuel sub-capsules [8]. 


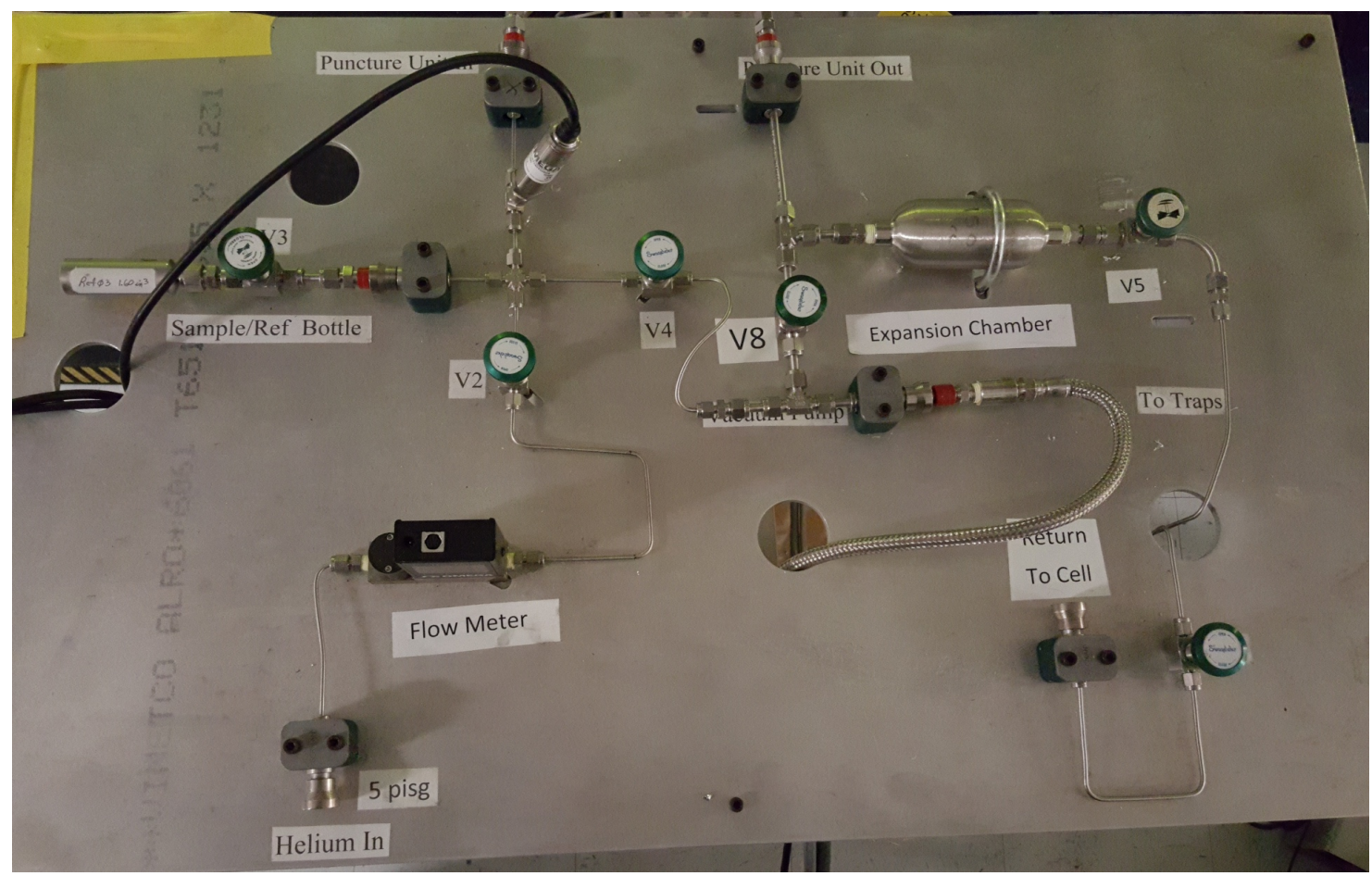

Figure 9. Schematic of gas puncture system with components labeled.

The MiniFuel gas puncture unit was designed solely to puncture the miniature fuel sub-capsules, which may range in diameter from $7.90 \mathrm{~mm}-9.52 \mathrm{~mm}$ depending on the specific fuel geometry contained inside the sub-capsule. The gas puncture unit is shown out-of-cell in Figure 10 ( $a$ and $b$ ) during testing. The sub-capsule is loaded from the top and the puncture pin is driven via screw thread into the subcapsule from the side until puncture occurs. The puncture device tip material and tip angle were tested and optimized for effective puncturing of the titanium housing of the sub-capsule with minimal dulling of the tip. The puncture tool has a heat-treated A2 steel $45^{\circ}$ tip and is pictured in Figure 11.

(a)

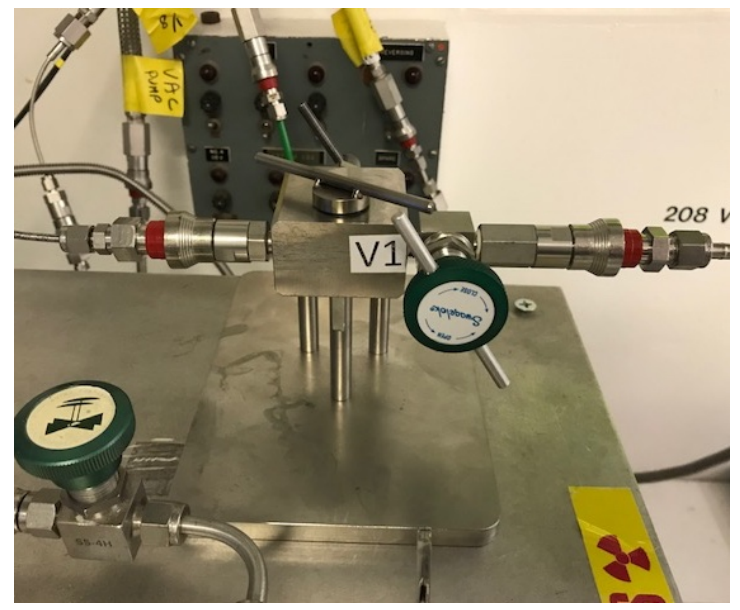

(b)

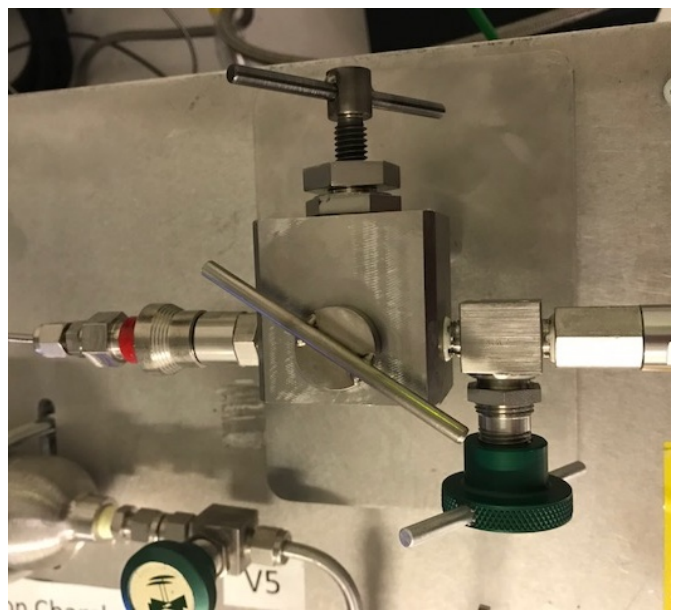

Figure 10. (a) Front and (b) top-down view of MiniFuel gas puncture unit shown out-of-cell during testing. 


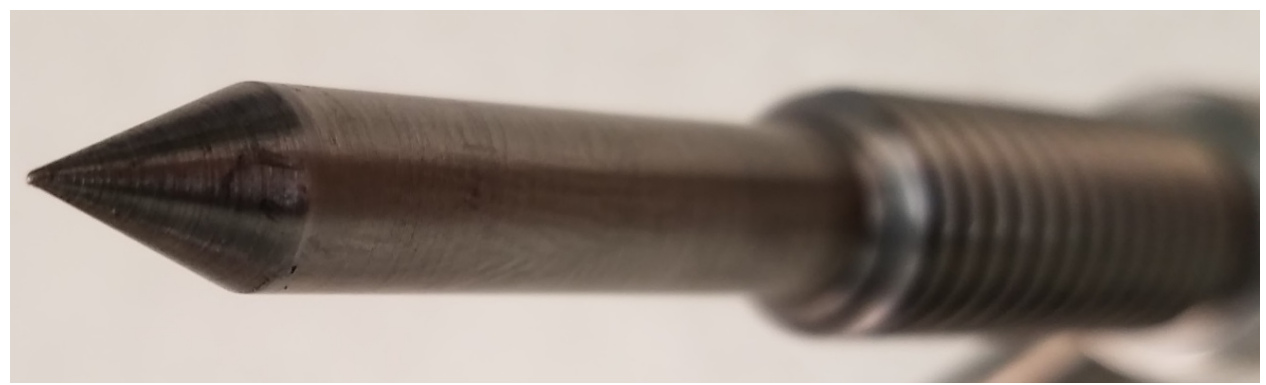

Figure 11. Puncture tool pictured after successful puncture with minimal dulling of the tip.

The charcoal cold traps are shown connected to the puncture system in Figure 12(a). The cold traps are cooled in liquid nitrogen during the test in order to freeze and collect the fission gas. The traps are then disconnected, brought to room temperature, and put inside of a germanium detector (Figure 12(b)) for counting. A Europium standard is used to calibrate the detector to the gamma energy peak range expected from krypton- 85 ( $\mathrm{t}_{1 / 2}=10.6$ years), which is the fission gas with the longest half-life and therefore most likely to be detected based on reasonable cooldown times.

(a)

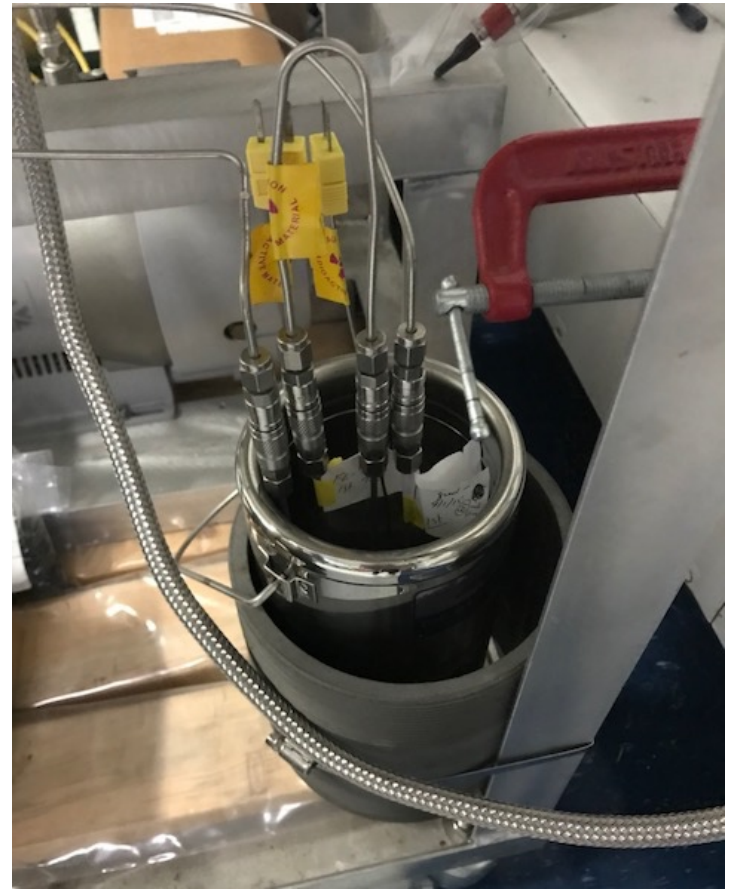

(b)

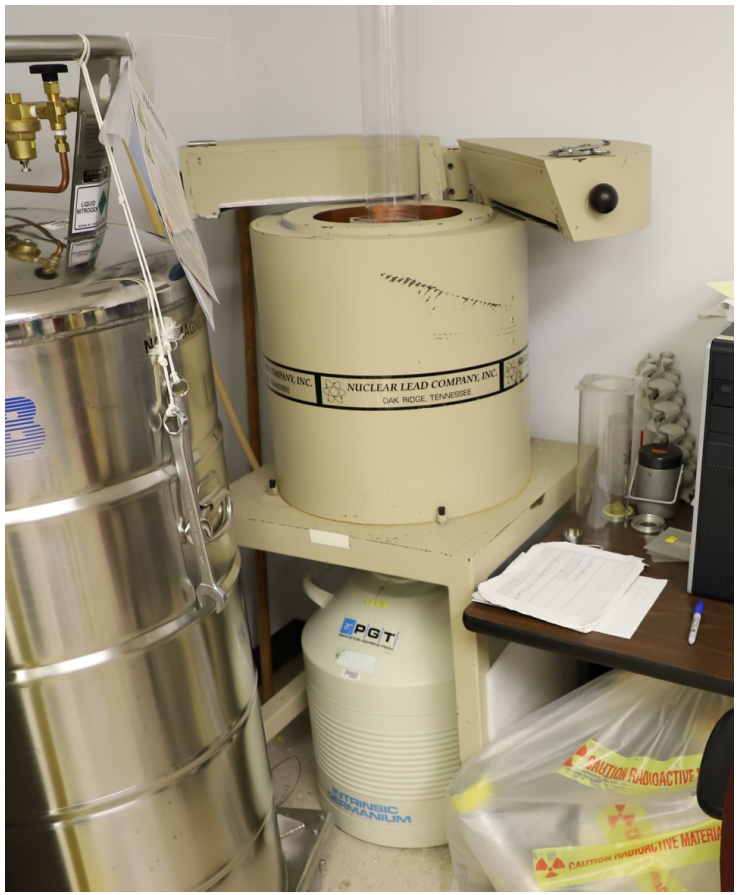

Figure 12. (a) Charcoal cold traps used to collect krypton gas and (b) the germanium detector used for counting the radioactivity from the gas.

\subsection{DETECTION LIMITATIONS}

Since the size of the miniature fuel specimens is so small, the amount of fission gas released is expected to be minimal. Therefore, the ability to detect the fission gas release with confidence was calculated and confirmed to validate this method for use. First, the minimum detection limit (counts) that the detector is capable of distinguishing from the background was calculated. Currie [9] has defined the determination limit $\left(L_{Q}\right)$ for radioactivity with regards to the background of a measurement as, 


$$
L_{Q}=\frac{k_{Q}^{2}}{2}\left\{1+\left[1+\frac{4 \sigma_{0}^{2}}{k_{Q}^{2}}\right]^{1 / 2}\right\}
$$

where $k_{Q}{ }^{-1}$ is the desired relative standard deviation, and $\sigma_{Q}$ is the standard deviation of the background spectrum near the Kr-85 gamma peak $(514 \mathrm{keV})$. For the germanium detector that will be used in this analysis, $k_{Q}{ }^{-1}$ is assumed to be 0.33 and $\sigma_{Q}$ is 18 counts, which is the standard deviation of the background spectrum over 6 hours. The determination limit, $L_{Q}$, is therefore calculated to be 58.7 counts for a 6 -hour period of counting. This means that at least 58.7 counts need to be made to be able to distinguish the $\mathrm{Kr}$ 85 gamma signal from background.

The germanium detector efficiency in use at IFEL is $1.62 \times 10^{-3}$; therefore, a total of $3.63 \times 10^{4}$ gamma rays must be emitted in order for the detector to achieve the 58.7 counts. Krypton- 85 emits a gamma ray with a branching fraction of $0.43 \%$, so $8.44 \times 10^{6}$ disintegrations are needed over the 6 hours to produce $3.63 \times 10^{4} \mathrm{Kr}-85$ gamma rays. Converting this disintegration rate to activity, a minimum activity of $2.09 \mathrm{x}$ $10^{-2} \mu \mathrm{Ci}$ is required from the samples loaded inside of one sub-capsule to ensure detection.

The expected $\mathrm{Kr}-85$ fission gas release was calculated for representative fuels in the various geometries to determine whether the detection limit is below some value of projected release. The amount of $\mathrm{Kr}-85$ that is expected for each fuel geometry type based on fraction of fission gas release is plotted in Figure 13, which assumes the fuel contains depleted uranium, has 95\% theoretical density (TD), a krypton yield of 0.00286 (U-235), and reaches a burnup of $10 \mathrm{MWD} / \mathrm{kg} \mathrm{U}$.

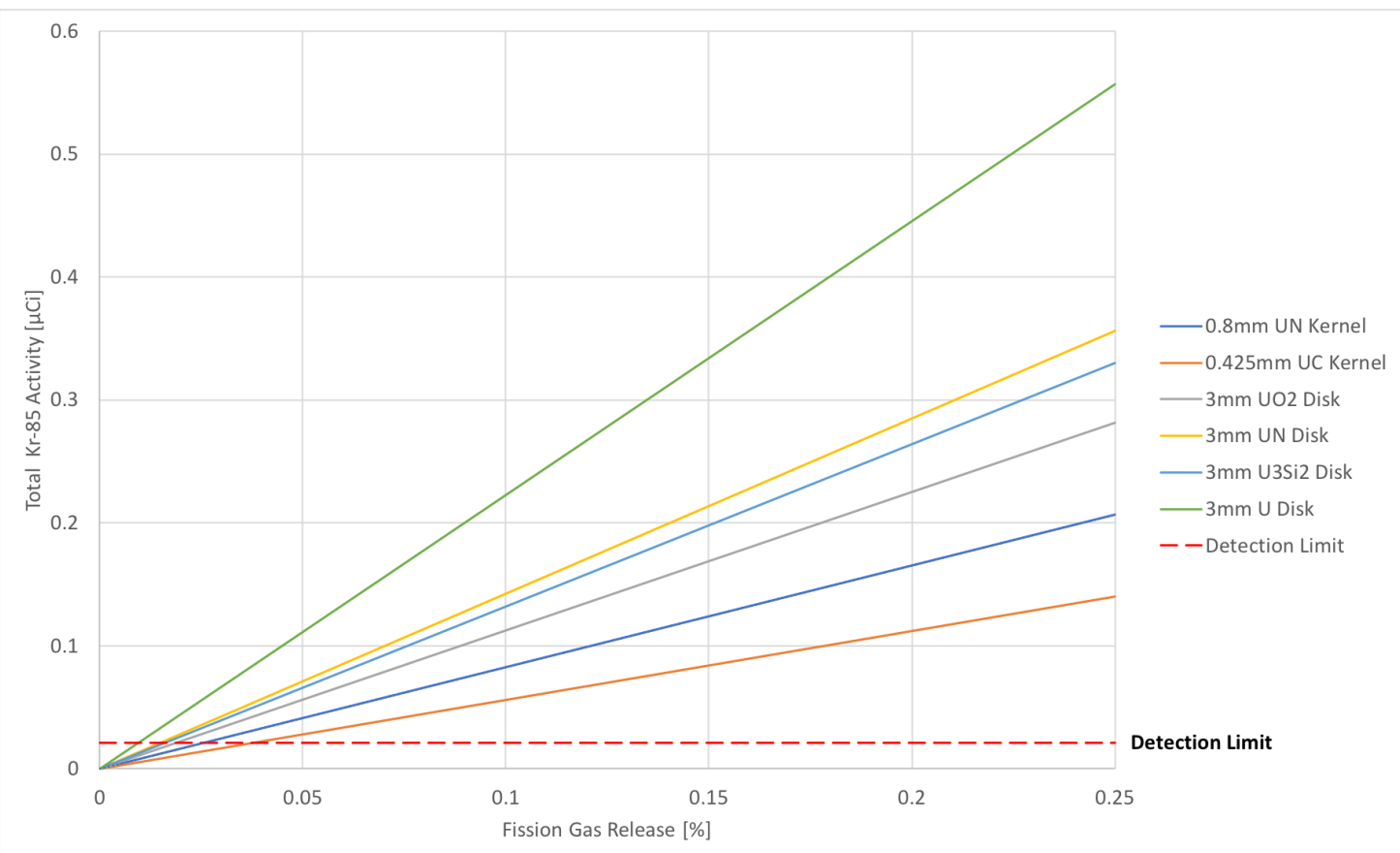

Figure 13. Calculated Kr-85 activity based on percentage of fission gas release.

Figure 13 shows that the calculated $\mathrm{Kr}-85$ activities for the various fuel types are above the theoretical detection limit for all fuels above approximately $0.04 \%$ fission gas release, indicating that the detection method should be successful for a range of geometries, given the fission gas release fraction is above this value. The detected amount of $\mathrm{Kr}-85$ will be compared to the theoretically produced amount to determine the percentage of gas released from the fuel. Fission gas release from the TRISO particles is not expected to occur unless there is a particle coating failure during irradiation. 


\subsection{PUNCTURE TEST RESULTS}

Two titanium MiniFuel sub-capsules, one empty and one loaded with all contents, were backfilled with helium to atmospheric pressure and welded for testing in the gas puncture system. The sub-capsules were leak and bubble tested after welding to ensure that no leaks were present. For testing, each sub-capsule was loaded into the system and taken through the entire procedure (except trap cooling) for puncturing. The system was initially brought under vacuum and checked for stability to ensure there were no leaks in the system. The full procedure for puncturing includes [8]:

- Loading target and preparation

- Determining tare volume $\left(V_{T}\right)$

- Trap purge and cool-down

- Puncture

- Pin purge and gas collection

- Plenum volume estimation $\left(V_{c p}\right)$

The puncture unit is isolated with the transducer and held under vacuum before puncture. The puncture is done by turning the puncture tool by approximately a $1 / 8$ turn at a time until the pressure is fully released and stabilized. Figure 14 shows the evolution of pressure during a test puncture of a sub-capsule that was filled with contents exact to those used in the MiniFuel sub-capsules and backfilled with helium to atmospheric pressure. The test sub-capsules were filled to atmospheric pressure since this is expected to be the minimum pressure after irradiation for the case of no fission gas release into the sub-capsule plenum. These results confirm that the puncture tool is effective, the system can record the pressure release, and the flow system is operating correctly with no recordable leaks.

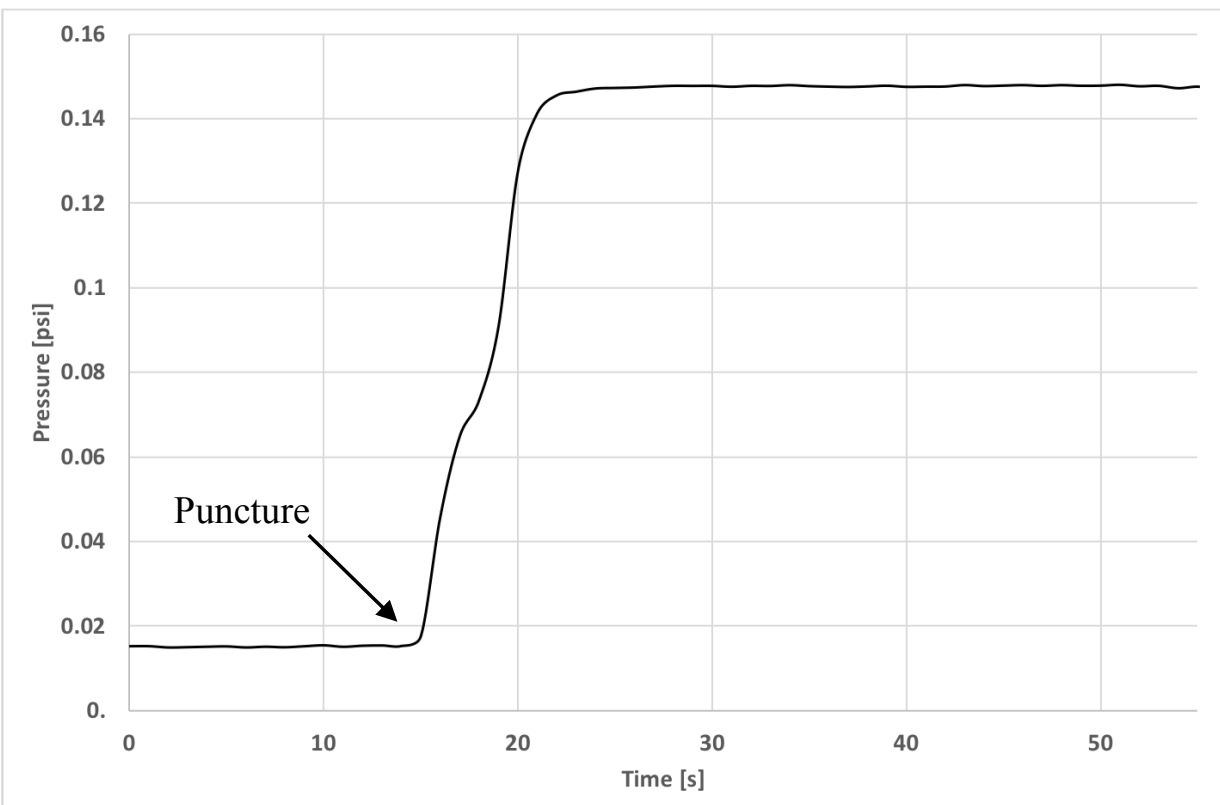

Figure 14. Pressure evolution during puncture of MiniFuel test sub-capsule. 
The tare volume and plenum volume estimation steps in the puncture procedure are used to back-calculate the magnitude of the pressure in the plenum before puncturing. These measurements are plugged into the equations listed in Appendix A to calculate the pressure inside the sub-capsule before puncture and the uncertainty. The pressure inside the empty MiniFuel sub-capsule was calculated to be 16.09 psi $(33.39 \%$ uncertainty) and pressure in the filled MiniFuel sub-capsule was calculated to be $21.99(161.28 \%$ uncertainty). The errors in these calculations are directly related to the ability to estimate the internal volume of the sub-capsule based on the change in pressure using methods of gas pycnometry. Unfortunately, the internal volume of the system is too large to make an accurate measurement of the plenum pressure for the MiniFuel sub-capsule. These methods of gas pycnometry degrade in accuracy when attempting to estimate the change in pressure caused by a small volume within a larger internal volume. The second test capsule has a larger error because it was filled with surrogate contents, causing the internal volume to be even smaller and more representative of the actual MiniFuel sub-capsules. While this pressure measurement would be useful as additional data on the irradiation behavior of the fuel, it is not necessary to estimate the fission gas release. It may be possible to reduce the internal volume of the piping and valves to a minimum value so that the sub-capsule plenum volume is more comparable to the isolated system free volume and a measurement with less uncertainty can be made. This possibility will be looked into as an upgrade to the puncture system in the future.

\section{FUEL SWELLING}

Fuel swells during irradiation due to the creation and build-up of the solid and gaseous fission products in the fuel materials. Fuel swelling is often used as a parameter to evaluate the safety and performance of a fuel type, since swelling has direct implications on fuel mechanical and thermal properties. Swelling of the fuel can also cause a closure of the gap between the fuel and cladding materials, subsequently causing pellet-clad mechanical interaction (PCMI). PCMI is a result of the stresses due to contact between the two materials and the corrosive behavior of the fission products on the cladding. The degradation from PCMI can potentially cause cladding fracture during normal and abnormal reactor operating conditions [10]. According to the defense-in-depth theory, the cladding is the first safety barrier to the release of radioactivity in an LWR, so any degradation to this material must be understood. Therefore, the extent of fuel swelling during irradiation is an important material property to analyze for fuel development. The measurement of the fuel swelling resulting from irradiation consists of a comparison between the preirradiation and post-irradiation fuel volume.

Methods for determining sample volume are often coupled with density determination methods, with mass typically being the easier measurement. Accurate methods for determination of the density of very small $\left(<1 \mathrm{~cm}^{3}\right)$ specimens are limited and include mercury pycnometry [11], comparison with heavy liquids [12], and various flotation methods [13]. Many of these methods involve the use of toxic substances, require highly complex designs, or necessitate the immersion of the material in some liquid, resulting in material destruction; any of these are undesirable in methods used for post-irradiation examination at a hot cell facility with a limited number of specimens. The use of toxic substances is typically banned in hot cells and immersion of the materials would effectively destroy the material before microstructural characterization can take place. For this reason, a method was developed at ORNL for the volume measurement of MiniFuel specimens using X-ray Computed Tomography (XCT), which has the benefit of being non-destructive.

\subsection{XCT METHOD DESCRIPTION}

Object volume measurement using XCT consists of two steps: sample imaging and image segmentation. Sample imaging was performed using an x-ray microtomography instrument (Xradia MicroXCT-400) which collects a series of radiographs of the sample at various rotational angles. Each radiograph is a two-dimensional projection of the three-dimensional sample; however, a collection of radiographs 
spanning at least 180 degrees of sample rotation may be mathematically combined to reconstruct a threedimensional image of the sample. In this image, the brightness is proportional to the x-ray absorbance in each region, which in turn depends on local density and atomic number.

The following step of image segmentation was performed using custom software written with MATLAB. Filtering and morphological operations were used as a precursor step to reduce image noise and to enhance edges between materials, then brightness thresholds for each material were determined using Otsu's method, an algorithm that reduces a grayscale image to a binary image [14]. These automatically generated thresholds that were verified or modified by user input, then used to segment the threedimensional image into groupings of voxels (three-dimensional pixels) of the same material which could be tabulated with the known image scale to determine material volumes. For monolithic materials, this is the final step; however, for more complex materials, segmentation was more complex.

In the case of tristructural isotropic (TRISO) particles, the known geometry (concentric spherical shells) was used to guide segmentation. The silicon carbide $(\mathrm{SiC})$ layer and the kernel were readily segmented from the rest of the image due to their significantly higher atomic numbers than the buffer, Inner Pyrolytic Carbide (IPyC), and Outer Pyrolytic Carbide (OPyC) layers. This left the buffer/IPyC interface and the $\mathrm{OPyC} /$ Exterior interfaces to be determined. Determination of these interfaces was more challenging due to the similarity in brightness between the adjoining layers. This challenge was resolved by making an initial estimate of the location of each interface based on the known locations of the kernel and SiC layer and the approximate thicknesses of each layer. All interfaces were then iteratively adapted across a range by determining the likelihood that each point was the true interface between the layers. This likelihood determination was based on local image statistics as well as the location of adjoining interface points in a three-dimensional analogue to the two-dimensional Coupled Bayesian Snakes method [15]. Figure 15 shows the resulting coloration of a TRISO particle and monolith tungsten carbide sample used for validation of the method.

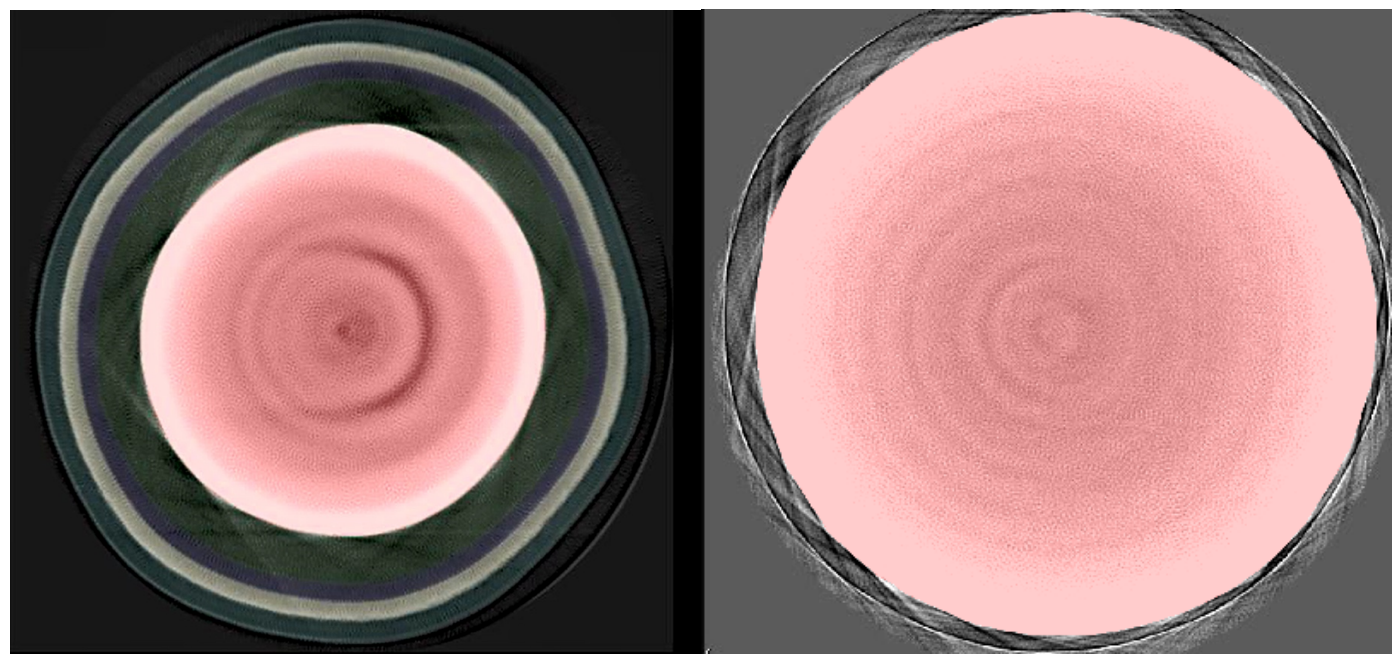

Figure 15. Cross-section of pre-irradiation UN TRISO tomograph with coloration of segmented layers (left) and cross-section of tungsten carbide standard tomograph (right). 


\subsection{VOLUME MEASUREMENT RESULTS}

Ball bearing standards of various materials were used for validating the ability of the XCT program to determine the monolith fuel material type volume. The standards were machined to a grade 25 , which means the machining was accurate to $25 / 1,000,000$ of an inch $(0.000635 \mathrm{~mm})$. Therefore, the geometrical volume of these samples can provide a good point for comparison to the output of the computed volume from the XCT program. The XCT system uses a $100 \mathrm{kV}$ tungsten $\mathrm{x}$-ray source operating at $40 \mathrm{kV}$ to provide the beam. Each specimen was analyzed using 3200 frames at an exposure rate of 15 seconds per frame, and the specimen was rotated $182^{\circ}$ about the vertical axis during analysis. The results for the ball bearing standards used during validation are shown in Table 1 . The volumes calculated for each ball using the XCT method are very close to the range of sizes expected due to the machining error for a grade 25 sphere. The maximum error in the calculated volume, assuming the worst-case machined dimension (or the dimension furthest from the XCT value), is less than $2.5 \%$ for all samples.

Table 1. Results for XCT software measurement of ball bearing standards of varying material and size.

\begin{tabular}{|c|c|c|c|}
\hline Material (Size) & Diameter Range $[\mathbf{m m}]$ & Volume Range $\left[\mathbf{m m}^{3}\right]$ & XCT Result $\left[\mathbf{m m}^{3}\right]$ \\
\hline $\mathrm{WC}(1 \mathrm{~mm})$ & $0.9994-1.0006$ & $0.5226-0.5246$ & 0.5202 \\
\hline $\mathrm{WC}(0.8 \mathrm{~mm})$ & $0.7994-0.8006$ & $0.2674-0.2687$ & 0.2688 \\
\hline $\mathrm{WC}(0.5 \mathrm{~mm})$ & $0.4994-0.5006$ & $0.0652-0.0657$ & 0.0668 \\
\hline $\mathrm{ZrO} 2(1 \mathrm{~mm})$ & $0.9994-1.0006$ & $0.5226-0.5246$ & 0.5185 \\
\hline $\mathrm{Si} 3 \mathrm{~N} 4(1 \mathrm{~mm})$ & $0.9994-1.0006$ & $0.5226-0.5246$ & 0.5164 \\
\hline
\end{tabular}

Further development of the XCT method will occur to include irregular shapes in the analysis. For a high degree of accuracy, each measurement takes approximately a day to complete, which would not be efficient when there are many fuel specimens in an experiment to analyze. For this reason, alternative methods for measuring the post-irradiation volume are being explored, including helium gas pycnometry.

The post-irradiation density can be calculated without a significant loss in accuracy as long as the balance is sufficiently accurate. A WXTP26 Mettler Toledo microbalance with a $1 \mu \mathrm{g}$ readability will be placed in-cell at IFEL and utilized for the mass measurement of the MiniFuel specimens.

\section{MICROSTRUCTURAL CHARACTERIZATION}

Microstructural characterization is used to analyze the microstructural changes in the fuel material due to irradiation. The metallography methods used for compact preparation are well established at ORNL due to work completed on behalf of the Advanced Gas Reactor (AGR) program, which is primarily focused on coated particle fuel [15]. These methods utilize equipment inside of the hot cell for preparation of compacts with potentially high radiation or contamination levels. Similar methods will be used to prepare and analyze the irradiated miniature fuel specimens, both kernel and disk geometry types.

The primary mode of sample preparation involves backpotting the specimen in epoxy to create a stable structure for polishing. The backpotting process has been optimized for fuel kernels through the use of a mounting form [15]. The specimen is placed into the mounting form and is held in place on the bottom by an upward facing piece of tape on the bottom of the form. The form is then filled with epoxy, placed under vacuum for a short time to de-gas the form, brought to atmospheric pressure to allow the epoxy to penetrate the specimen, and then set to cure for at least 24 hours. In the case of the fuel kernels, multiple specimens can be placed into one mount, depending on the size of the mounting form. Figure 16 shows 
two sizes of mounting forms; the form with the $3.18 \mathrm{~mm}$ diameter stub size is the ideal size for mounting one or two particles and the $6.35 \mathrm{~mm}$ diameter stub size is ideal for multiple particles or the $3 \mathrm{~mm}$ disk geometry specimens.

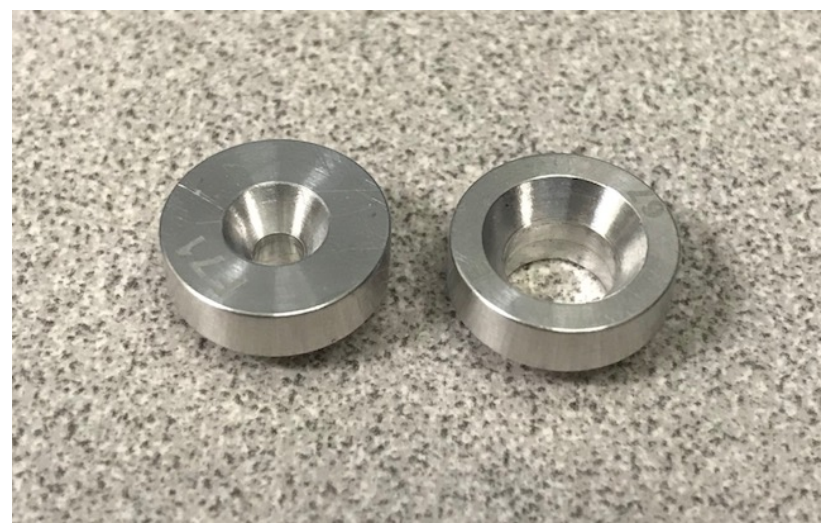

Figure 16. Two sizes of aluminum mounting forms (3.18 $\mathrm{mm}$ diameter stub and $6.35 \mathrm{~mm}$ diameter stub) that can be used to mount irradiated fuel kernels in epoxy.

After the backpotting step is complete, the specimen is polished down to mid-plane using a Buehler Minimet 1000 polisher (Figure 17(a)), which is outfitted with a precision thinning attachment. The mounting form fits directly into the thinning attachment, which is shown in Figure 17(b). There is an optical microscope located in-cell with the polisher, which allows the operator to observe the progression of the polish after each step. The polishing procedure uses consecutively smaller sized diamond polishes $(15 \mu \mathrm{m} \rightarrow 9 \mu \mathrm{m} \rightarrow 6 \mu \mathrm{m} \rightarrow 3 \mu \mathrm{m} \rightarrow 1 \mu \mathrm{m} \rightarrow 0.5 \mu \mathrm{m})$ to first cut the sample down to mid-plane and then polish to a finish required for SEM analysis. Samples intended for SEM are also typically polished with an extra step of $0.04 \mu \mathrm{m}$-colloidal silica suspension (OP-S), which produces slight chemical etching of the surface. The mounts are typically cleaned in an ultrasonic bath to remove any residue from the polishing steps.

(a)

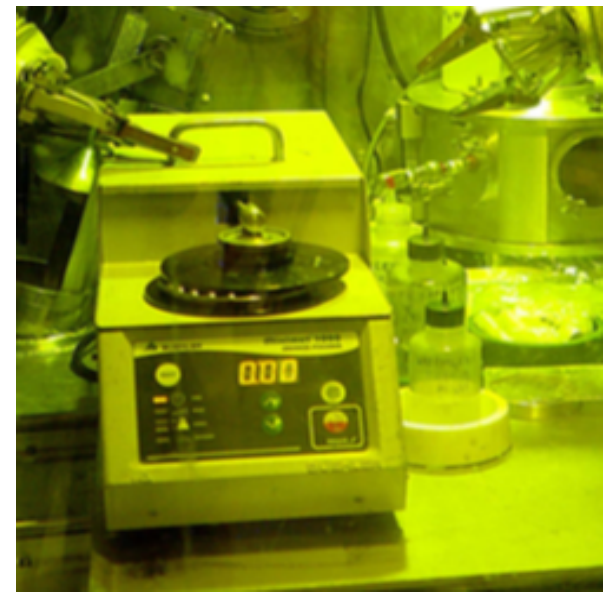

(b)

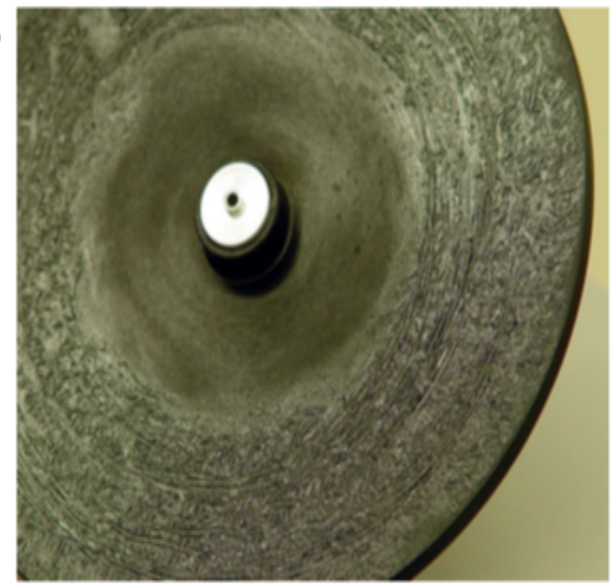

Figure 17. (a) Minimet polisher located in-cell and (b) the mounting form positioned inside of the thinning attachment for polishing [15]. 
If the fuel specimen dose is significantly high, then SEM analysis of the irradiated fuel can be done with a JEOL JSM-6390L SEM, which is located at IFEL. The mounts are placed in shielded pig containers for transfer to the SEM and stored in the pig until inserted into the SEM for analysis. This SEM is equipped with energy dispersive $\mathrm{x}$-ray spectroscopy (EDS) and wave dispersive x-ray spectroscopy (WDS) detectors. The SEM analysis can highlight features like the porosity formation and fission product distribution within the fuel microstructure. One benefit of having previously acquired XCT scans on the irradiated particles for the volume measurement is that this data can also be used locate defects in the particles that are of interest. After the defect has been located via XCT, the kernels can be polished down to these features for further characterization.

If the dose and contamination levels of the prepared MiniFuel specimens is low enough, then the suite of microscopes located in the LAMDA laboratory can be used for microstructural characterization. The characterization equipment in LAMDA includes multiple state-of-art Focused Ion Beams (FIBs) and Transmission Electron Microscopes (TEMs). These modern electron microscopy instruments have been recently used to characterize the microstructure of a commercial uranium dioxide fuel pellet and analyze the high burnup structure formation [16].

\section{SUMMARY AND FUTURE WORK}

This report summarizes the established capabilities and methodology for post-irradiation examination of the MiniFuel specimens. The methodology includes sub-capsule disassembly, retrieval of fuel specimens, post-irradiation characterization of the fission product behavior, and microstructural characterization of the specimens. These methods have been demonstrated and are ready to be implemented and used for PIE of the first set of irradiated MiniFuel specimens.

There are certainly opportunities to further develop the PIE methods established in this report. For example, the gas puncture system can be upgraded to reduce the internal volume of the segment isolated during the plenum pressure measurement. This would improve the accuracy in the calculated sub-capsule plenum pressure and provide another parameter for analysis of the fission gas release behavior. The limitations in the number of specimens (one per day) that can be analyzed using the XCT method will slow the production of results for larger irradiation campaigns. Therefore, alternative methods are currently under development for the post-irradiation volume measurement to circumvent this potential issue. The design of a helium micropycnometer is currently being tested and may be able to more efficiently measure the post-irradiation volume of specimens.

Development of additional methods for PIE will be ongoing in order to expand on the parameters that can be included in the separate effects testing using the MiniFuel design. The methods for analysis of fission product behavior have been outlined; however, there are still additional parameters that are desired for separate effects data, such as thermophysical and mechanical properties. There is adequate equipment for the measurement of thermophysical and mechanical properties currently located in LAMDA, but some upgrades to the methods to accommodate the small specimen size is likely necessary. The analysis methods will shift to addressing the disk specimen geometry as these samples become available for irradiation testing.

Near term (FY19-FY20) priorities for MiniFuel are twofold. First, the methods discussed in this document must be demonstrated for irradiated fuel. The various challenges and anticipated uncertainties discussed provide confidence that there are no fundamental hurdles to the goals of the project, but these must be executed to ensure that no unforeseen challenges or issues with the envisioned PIE techniques are found. Kernel irradiations are presently underway and will provide the first PIE baseline. The next phase of MiniFuel irradiations includes monolithic pellets in mid FY19. Resolution of both swelling and fission 
gas release will be challenged more by kernels than pellets given the volume difference, but the pellets may prove to be a greater challenge from the standpoint of disassembly and handling.

Second, the suite of PIE methods available to analyze MiniFuel specimens will be extended. An initial emphasis will be thermal conductivity given its importance to fuel behavior. Recent work performed by the DOE Fusion Materials Program demonstrated a capability to perform laser flash analysis measurements on small disks comparable to those of MiniFuel [17]. Activity of fuel samples will be more significant than structural materials, but this result is promising. Nanoindentation of irradiated fuel has already been performed using LAMDA capabilities [18]. Although hardness and elastic modulus are not of high importance or relevance to fuel behavior, these data can indicate general evolution in mechanical properties induced by fission products and other irradiation effects.

The FY19 Advanced Fuels Campaign planning packages include at least three level two milestones across multiple laboratories in support of MiniFuel development, including Los Alamos National Laboratory fabrication of $\mathrm{U}_{3} \mathrm{Si}_{2}$ MiniFuel samples, ORNL MiniFuel post-irradiation examination at IFEL, and an additional HFIR irradiation of monolithic fuel samples. 


\section{REFERENCES}

[1] U.S. Department of Energy. Development of Light Water Reactor Fuels with Enhanced Accident Tolerance, June 2015.

[2] Petrie, C., M., Burns, J., Morris, R., Terrani, K., Miniature Fuel Irradiations in the High Flux Isotope Reactor. Proceedings of the Enlarged Halden Programme Group Meeting, Lillehammer, Norway, 2017.

[3] Petrie, C., Burns, J., Morris, R., Terrani, K., Small-scale fuel irradiation testing in the high flux isotope reactor, Proceedings of the 2017 Water Reactor Fuel Performance Meeting, Jeju Island, Korea, 2017.

[4] Nelson, A., Petrie, C., Coordinated MiniFuel Irradiation Test Plan for Ceramic Fuels, Los Alamos National Laboratory and Oak Ridge National Laboratory, November 2017.

[5] Petrie, C.M., Burns, J.R., Morris, R.N., Smith, K.R., Le Coq, A.G., Terrani, K.A., Irradiation of Miniature Fuel Specimens in the High Flux Isotope Reactor, Oak Ridge National Laboratory, June 2018.

[6] Petrie, C., Burns, J., Morris, R., Terrani, K., Accelerated Irradiation Testing of Miniature Fuel Specimens, Nuclear Fuels and Structural Materials for the Next Geneartion Nuclear Reactors, Philadelphia, PA, 2018.

[7] Tonks, M., Andersson D., Devanathan, R., Dubourg, R., El-Azab, A., Freyss, M., Iglesias, F., Kulacsy, K., Pastore, G., Phillpot, S., Welland, M., Unit mechanisms of fission gas release: current understanding and future needs, Journal of Nuclear Materials, 204 (2013) 300-317.

[8] Morris, R.N., General Target Puncturing and Sample Operating Guideline, Oak Ridge National Laboratory, FMNSD-PRO-48.

[9] Currie, L.A, Limits for qualitative detection and quantitative determination, Analytical Chemistry, 40 (1968) 586-593.

[10] Massih, A.R., Linkback, J.E., Jernkvist, L.O., Zhou, G., Analysis of pellet-clad interaction of LWR fuel rods during power ramps, $18^{\text {th }}$ International Conference on Structural Mechanics in Reactor Technology, Beijing, China, August 2005.

[11] Yamagishi, S., Takahashi, Y., Shiba, K., An accurate method for determining the small volumes of granular solids by mercury pycnometry, Journal of Physics E: Scientific Instruments, 17 (1984) 339-341.

[12] Franklin, A.D., Spal, R., A method for precision comparison of the densities of small specimens, The Review of Scientific Instruments, 42 (1971) 1827-1833.

[13] Schoonover, R., The density determination of small solid objects by a simple float method, Journal of Research of the National Bureau of Standards, 87 (1982) 197-206.

[14] Kittler, J., Illingworth, J., On threshold selection using clustering criteria, IEEE Transactions on Systems, Man, and Cybernetics, 15 (1985) 652-655. 
[15] Hunn, J.D., Morris, R.N., Baldwin, C.A., Montgomery, F.C., Silva, G.W.C., Gerczak, T.J., AGR-1 Irradiated Compact 4-4-2 PIE Report: Evaluation of As-Irradiated Fuel Performance with Leach Burn Leach, IMGA, Materialography, and X-ray Tomography, Oak Ridge National Laboratory, September 2013.

[16] Gerczak, T., Parish, C.M., Edmondson, P.D., Baldwin, C., Terrani, K.A., Restructuring in high burnup $\mathrm{UO}_{2}$ studied using modern electron microscopy, Journal of Nuclear Materials, 509 (2018) 245259.

[17] Akiyoshi, M., Kasada, R., Ishibashi, Y., Garrison, Lauren., Geringer, J., Porter, W., Katoh, Y., Validations of minature test specimens for post-irradiation thermal diffusivity measurement, Fusion Engineering and Design, 2018 (article in-press).

[18] Terrani, K., Balooch, M., Burns, J., Smith, Q., Young's modulus evaluation of high burnup structure in $\mathrm{UO}_{2}$ with nanometer resolution, Journal of Nuclear Materials, 508 (2018) 33-29.

[19] Morris, R.N., Full Length LWR Rod Pressure and Volume Measurement, Oak Ridge National Laboratory, SS-GP-001. 
Development of a characterization methodology for

\section{APPENDIX A: GAS PUNCTURE EQUATIONS}


The following derivations have been adapted for use on the MiniFuel sub-capsule from [19]:

\section{Tare Volume}

Since the puncture unit and connecting lines are brought down to vacuum except for sample bottle $\left(V_{s b}\right)$, the moles of gas in the system at the initial sample bottle pressure $\left(P_{i}\right)$ for a constant temperature is measured by (from ideal gas law $P V=n R T$ ):

$$
P_{i} V_{s b}
$$

When the values are opened, the pressure $P_{e}$ drops as the gas expands to fill the tare volume $\left(V_{T}\right)$ (constant temperature) so that the moles of gas in each volume sum to the total:

$$
P_{i} V_{s b}=P_{e}\left(V_{s b}+V_{T}\right)
$$

Solving gives:

$$
V_{T}=V_{s b}\left(\frac{P_{i}}{P_{e}}-1\right)
$$

\section{Sub-capsule Volume}

Since the puncture unit, connecting lines, and sub-capsule plenum $\left(V_{c p}\right)$ are brought down to vacuum except for sample bottle $\left(V_{s b}\right)$, the moles of gas in the system at the initial sample bottle pressure $\left(P_{i}\right)$ for a constant temperature is measured by:

$$
P_{i} V_{s b}
$$

When the valves are opened, the pressure $P_{e}$ drops as the gas expands to fill the tare volume $\left(V_{T}\right)$ and the sub-capsule plenum $\left(V_{c p}\right)$ (constant temperature) so that the moles of gas in each volume sum to the total:

$$
P_{i} V_{s b}=P_{e}\left(V_{s b}+V_{c p}+V_{T}\right)
$$

Solving gives:

$$
V_{c p}=V_{s b}\left(\frac{P_{i}}{P_{e}}-1\right)-V_{T}
$$

Note: This step is performed after puncture of sub-capsule is complete. 


\section{Sub-capsule Pressure}

Since the puncture unit and connecting lines are brought down to vacuum, the moles of gas in the system at the sub-capsule volume $V_{c p}$ and the sub-capsule pressure $P_{c p}$ for a constant temperature is measured by:

$$
P_{c p} V_{c p}
$$

When the sub-capsule is punctured, the pressure in the system after puncture $\left(P_{p}\right)$ increases as the gas expands to fill the tare volume $\left(V_{T}\right)$ so that the moles of gas in each volume sum to the total:

$$
P_{c p} V_{c p}=P_{p}\left(V_{c p}+V_{T}\right)
$$

Solving gives:

$$
P_{c p}=\frac{P_{p}}{V_{c p}}\left(V_{c p}+V_{T}\right)
$$

Note that this is a two-step process; first the sub-capsule is punctured and the puncture values are recorded $\left(P_{p}\right)$ and then the sub-capsule is back filled to determine the volume $\left(V_{c p}\right)$.

\section{Uncertainty Estimation}

If one assumes that $\mathrm{V}_{\mathrm{sb}}$ has negligible uncertainty, then (using the appropriate task initial and ending pressures):

$$
\Delta V_{T}=V_{s b} \frac{P_{i}}{P_{e}}\left[\left(\frac{\Delta P_{i}}{P_{i}}\right)^{2}+\left(\frac{\Delta P_{e}}{P_{e}}\right)^{2}\right]^{1 / 2}
$$

The uncertainty in the plenum volume is:

$$
\Delta V_{c p}=\left[\left(\frac{V_{s b} P_{i}}{P_{e}}\right)^{2}\left[\left(\frac{\Delta P_{i}}{P_{i}}\right)^{2}+\left(\frac{\Delta P_{e}}{P_{e}}\right)^{2}\right]+\left(\Delta V_{T}\right)^{2}\right]^{1 / 2}
$$

The uncertainty in the capsule pressure is:

$$
\Delta P_{c p}=P_{p}\left[\left(1+\frac{V_{T}}{V_{c p}}\right)^{2}\left(\frac{\Delta P_{p}}{P_{p}}\right)^{2}+\left(\frac{\Delta V_{c p}}{V_{c p}}\right)^{2}+\left(\frac{V_{T} \Delta V_{c p}}{V_{c p}^{2}}\right)^{2}\right]^{1 / 2}
$$

